\title{
Effect of Melatonin on Testicular Damage in Streptozotocin-Induced Diabetes Rats
}

\author{
E. Gunelia K. Tugyan ${ }^{b} \quad$ H. Ozturk ${ }^{e} \quad$ M. Gumustekin ${ }^{c} \quad$ S. Cilaker ${ }^{b} \quad$ N. Uysal ${ }^{d}$ \\ a Department of Laboratory Animal Science, Institute of Health Science, and Departments of b Histology and \\ Embryology, 'Pharmacology and dPhysiology, School of Medicine, Dokuz Eylul University, Izmir, and \\ e Department of Pediatric Surgery, Medical School, Abant Izzet Baysal University, Bolu, Turkey
}

\section{Key Words}

Diabetic testes injury · Melatonin · Germ cell apoptosis •

Streptozotocin

\begin{abstract}
Background: It is well known that diabetes mellitus is associated with impairment of testicular function. In the present study, we aimed to demonstrate the effect of melatonin on testicular damage in male rats with streptozotocin (STZ)-induced diabetes. Methods: Male Wistar rats were divided into 4 groups: (1) control group, (2) melatonin-treated nondiabetic group, (3) diabetic group and (4) melatonin-treated diabetic group. Diabetes was induced by STZ injection. Melatonin was administered intraperitoneally at the dose of 10 $\mathrm{mg} / \mathrm{kg}$ for 5 days. Testicular damage was examined by using hematoxylin and eosin staining and periodic acid-Schiff staining, and apoptosis was determined by terminal-deoxynucleotidyl-transferase-mediated dUTP nick end labeling (TUNEL). Potential disorders associated with seminiferous tubular sperm formation were evaluated using the Johnsen score. Results: Diabetic rats showed a reduction in seminiferous tubule diameter, increased thickening of the basement membrane in seminiferous tubules and degenerated germ cells. TUNEL-positive cells were significantly more numerous in diabetic rats than in control rats. Melatonin significantly attenuated the diabetes-induced morphological changes and germ cell apoptosis in the diabetic rat testis. The number of polymorphonuclear leukocytes was signifi-
\end{abstract}

cantly decreased in group 4 when compared to group 3 . Conclusions: These results suggest that intraperitoneal administration of melatonin for 5 days is a potentially beneficial agent to reduce testicular damage in adult diabetic rats, probably by decreasing oxidative stress.

Copyright $\odot 2008$ S. Karger AG, Basel

\section{Introduction}

Diabetes mellitus is a common health problem and a serious metabolic disorder associated with many functional and structural complications. Diabetes mellitus has adverse effects on male sexual and reproductive functions in diabetic patients and animals [1-4]. Both clinical and experimental studies revealed impairment of spermatogenesis, reduced sperm count, sperm motility, seminal fluid volume and low testosterone levels in diabetic subjects [1-6]. Additionally, an experimental study indicated that diabetes mellitus produces reproductive dysfunction but does not compromise the sperm-fertilizing ability in the cauda epididymis [7].

Apoptosis, known as programmed cell death, is a form of cell death that serves to eliminate dying cells in proliferating or differentiating cell populations. Apoptosis control is critical for normal spermatogenesis in the adult testes $[6,8]$. The testis is sensitive to environmental exposure-induced cellular damage. Apoptosis of germ cells may occur during nonphysiological stresses such as dia-

\section{KARGER}

Fax +4161306 1234 E-Mail karger@karger.ch www.karger.com

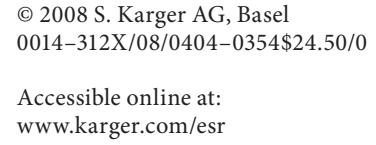

Hayrettin Ozturk, MD

Department of Pediatric Surgery, Medical School, Abant Izzet Baysal University

TR-14280 Bolu (Turkey)

Tel. +90 37425346563220 , Fax +90 3742534615

E-Mail ozturkhayrettin@hotmail.com 
betes, ischemia, hyperthermia and radiation $[9,10]$. Recent studies have shown increased apoptosis in the seminiferous tubule of streptozotocin (STZ)-induced diabetic mice and rats $[3,9,11]$. The mechanisms of diabetes-related apoptosis are unclear. However, current studies have indicated that diabetes-mediated oxidative stress can induce apoptosis $[12,13]$. Melatonin, a pineal hormone, has antioxidant and anti-inflammatory effects on various pathophysiological conditions [13]. The antiapoptotic effects of melatonin have been demonstrated in several experimental studies [14-16]. Thus, the aim of this study was to investigate the effects of exogenous melatonin on diabetes-induced testicular damage in diabetic rats.

\section{Materials and Methods}

Adult Wistar albino male rats (6-8 months old and weighing $230-260 \mathrm{~g}$ ) were used in the study. The animals were maintained under standard colony conditions with a 12 -hour light/12-hour dark cycle (lights on at 7:00 h) at constant room temperature (23 $\left.\pm 2{ }^{\circ} \mathrm{C}\right)$ and humidity $(60 \%)$, and given ad libitum access to food and water. All experiments were performed in accordance with the guidelines provided by the Experimental Animal Laboratory and approved by the Animal Care and Use Committee of Dokuz Eylul University School of Medicine.

\section{Experimental Design and Procedures}

STZ was used to induce diabetes as described previously [17]. Freshly prepared STZ (dissolved in citrate buffer of pH 4.5) in a dose of $45 \mathrm{mg} / \mathrm{kg}$ was administered intraperitoneally to the rats. An equal volume of vehicle (citrate buffer solution) was injected alone to each of the nondiabetic rats. On the 3rd or 4th day after STZ administration, nonfasting serum glucose levels were measured using a Medisense Optium glucometer (Roche Diagnostic, Germany). Rats with blood glucose levels higher than $300 \mathrm{mg} / \mathrm{dl}$ were considered to be diabetic.

Fourteen weeks after diabetes inducement, it was considered that chronic diabetes had been induced. Control and diabetic rats were assigned to 2 subgroups randomly $(n=20)$. One of these 2 subgroups was treated with melatonin $(10 \mathrm{mg} / \mathrm{kg}$, i.p.) for 5 days. Melatonin (Sigma, St. Louis, Mo., USA) was dissolved in absolute ethanol and diluted with physiological saline. The concentration of ethanol in the final solution was $5 \%$. The melatonin solution was administered at the dose of $10 \mathrm{mg} / \mathrm{kg}(5 \mathrm{ml} / \mathrm{kg}$, i.p.). Control and diabetic groups received vehicle only (5\% ethanol, $5 \mathrm{ml} / \mathrm{kg}$, i.p.). Experimental groups were: (1) control group, (2) melatonintreated nondiabetic group, (3) diabetic group and (4) melatonintreated diabetic group. All drug administrations and sacrificing procedures were performed between 9:00 and 11:00 h to reduce the effects of circadian rhythm.

At the end of the 6th day, the rats were sacrificed by cardiac puncture under ether anesthesia and transcardially perfused with heparinized saline followed by $10 \%$ formalin in phosphate buffer. Following the perfusion process, testes were removed and stored in the same solution for $24 \mathrm{~h}$. Testis tissues were processed by routine histological methods and embedded in paraffin blocks. Paraffin blocks were placed in Leica RM-2255 (Köln, Germany), and $5-\mu \mathrm{m}$-thick coronal sections were obtained. The sections of testis were stained with hematoxylin-eosin and mounted in Entellan mounting medium. The images were analyzed by using a computer-assisted image analyzer system consisting of a microscope (Olympus BX50, Tokyo, Japan), and the images were transferred into the computer using a digital video camera (JVC TK$890 \mathrm{E}$, Japan)

The sections of testis were also incubated in $0.1 \%$ periodic acid for 5-10 min. The slides were washed in running tap water and immersed in Schiff's reagent for $15 \mathrm{~min}$. Subsequently, the sections were washed in tap water for $10 \mathrm{~min}$, counterstained with Mayer's hematoxylin, washed in tap water and dehydrated in graded ethanol. Finally, the sections were cleared in xylene and mounted with Entellan.

\section{Examination of Spermatogenesis}

Johnsen's score was used to categorize the spermatogenesis [18]. It applies a grade from 1 to 10 to each tubule cross section according to the following criteria: $10=$ complete spermatogenesis and perfect tubules; $9=$ many spermatozoa present and disorganized spermatogenesis; 8 = only a few spermatozoa present; $7=$ no spermatozoa but many spermatids present; $6=$ only a few spermatids present; $5=$ no spermatozoa or spermatids but many spermatocytes present; $4=$ only a few spermatocytes present; $3=$ only spermatogonia present; 2 = no germ cells but only Sertoli cells present; 1 = no germ cells and no Sertoli cells present.

Measurement of Seminiferous Tubule Diameter

The 10 most circular seminiferous tubules were randomly identified in each section of the testis, and their diameters were measured with an ocular micrometer using the $\times 10$ lens. The mean seminiferous tubule diameter in micrometers was determined for each testis.

Measurement of Seminiferous Tubule Basement Membrane

Five-micrometer-thick sections obtained from each animal were stained with periodic acid-Schiff. All sections were viewed under a microscope with an attached video camera and image analyzer system (UTHSCA Image Tool for Windows version 3.0 software). The measurement was performed on 50 randomly selected seminiferous tubule basement membranes (STBM) from 3 randomly taken sections and averaged.

\section{Measurement of Apoptosis}

Apoptosis was evaluated by the in situ terminal-deoxynucleotidyl-transferase-mediated dUTP digoxigenin nick end labeling (TUNEL) assay. A Dead End Colorimetric TUNEL system kit (cat. No. 11684817 910; Roche) was used for apoptotic cell detection. Briefly, serial 5 - $\mu$ m-thick paraffin-embedded sections were deparaffinized, rehydrated in graded alcohol and microwave pretreated in trypsin solution at $37^{\circ} \mathrm{C}$ for $10 \mathrm{~min}$ (Roche; No. 10109 819 001). After being washed in phosphate-buffered saline, the specimens were incubated with fluorescein-labeled deoxy-UTP and terminal deoxynucleotidyl transferase at $37^{\circ} \mathrm{C}$ for $60 \mathrm{~min}$. Subsequently, converter POD solutions were applied to the slides. Sections were stained with diaminobenzidine, counterstained with hematoxylin and mounted with Entellan. Detection of apoptotic cells was performed manually under the light microscope 
Fig. 1. Representative photomicrographs of hematoxylin-eosin-stained sections in the testes of rats. a Control group. b Melatonin-treated nondiabetic group. c Diabetic group. d Melatonin-treated diabetic group. When compared with the diabetic group, the germinal cells in the examined regions appear well preserved in the melatonin-treated diabetic group.

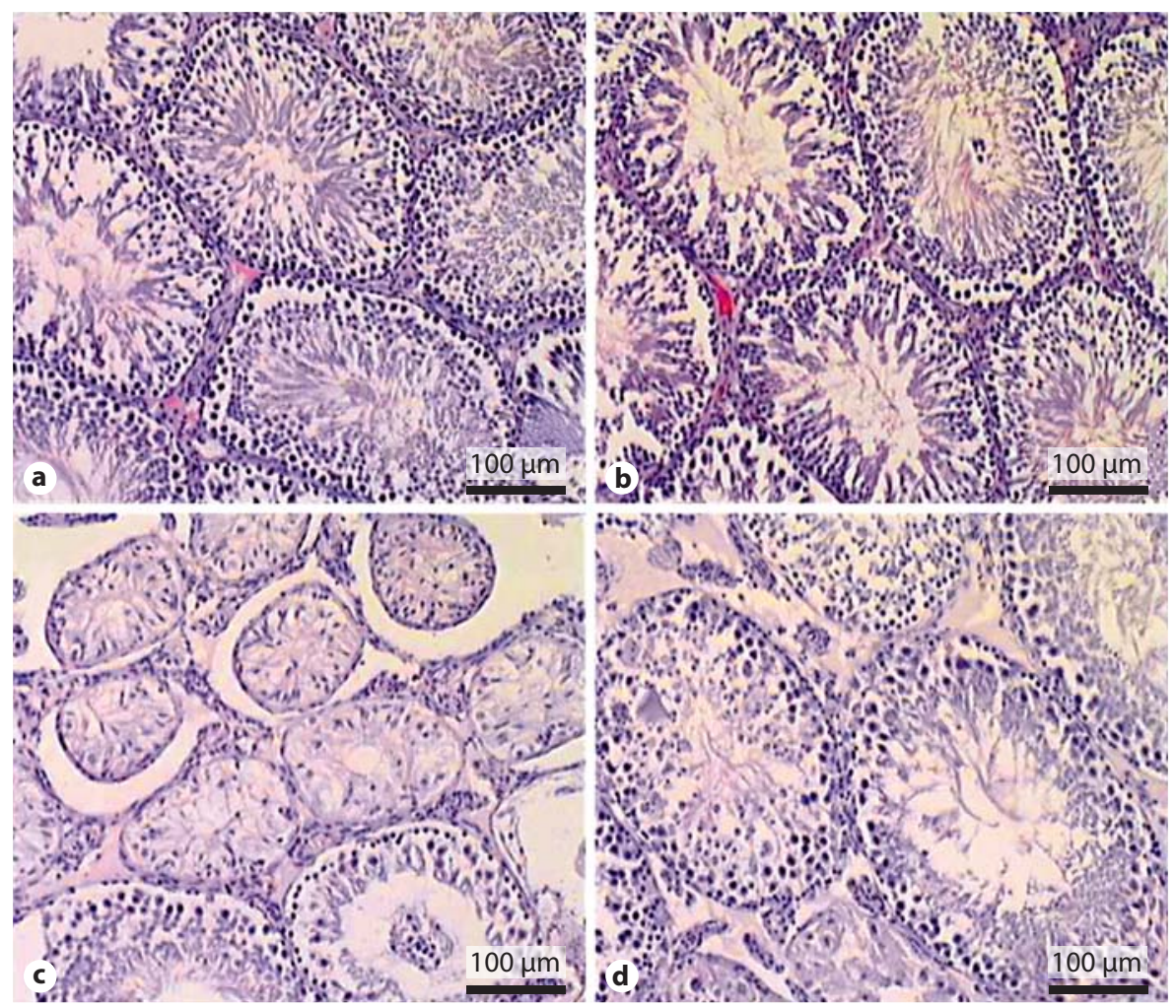

at a magnification of $\times 400$. In order to obtain the apoptotic index, TUNEL-positive cells in seminiferous tubules (100 per animal) in 10 randomly chosen fields were counted, aided by a grid of 100 squares. The apoptotic index was calculated as the percentage of cells showing TUNEL positivity. An observer blinded to the source of testicular tissue performed all measurements.

The severity of neutrophil infiltration was estimated, and the number of infiltrating neutrophils was assessed by counting neutrophils manually at a magnification of $\times 400$ (Olympus Eyepiece Micrometer $\left.{ }^{\circledR}\right)$ in 10 testes tissue areas per slide $(n=10$ in each group).

\section{Statistical Analysis}

Statistical analysis was performed using computerized software (SPSS version 11.0, Chicago, Ill., USA). The difference between the groups concerning the histopathological parameters was tested by one-way analysis of variance followed by post hoc Tukey's HSD test. Body weight and blood glucose levels were analyzed by the unpaired Student's t test. Results are presented as means \pm SEM. $\mathrm{p}<0.05$ was considered significant.

\section{Results}

Diabetic animals exhibited many symptoms commonly associated with diabetes (e.g. polyuria, polydipsia and diarrhea). Body weight values were found as $300 \pm$
15.9 and $218 \pm 15.6 \mathrm{~g}$ in the nondiabetic and diabetic groups, respectively. Blood glucose levels were found as $168 \pm 3.2$ and $445 \pm 22.6 \mathrm{mg} / \mathrm{dl}$ in the nondiabetic and diabetic groups, respectively. On the day of sacrifice, diabetic animals showed a lower body weight gain $(p<0.01)$ and hyperglycemia $(\mathrm{p}<0.0001)$ when compared with nondiabetic animals.

\section{Evaluation of Hematoxylin-Eosin Staining}

It was observed that the testis tissue in the control group was covered with an albugineous layer and the complete seminiferous tubule cell series was present (fig. 1a). The histological structure in the melatonintreated nondiabetic group resembled that of the control group (fig. 1b). The seminiferous tubule structure in the diabetic rats was found to be disrupted, and there was a considerable decrease in the spermatogenic cell series (fig. 1c). The number of spermatogenic cells in the melatonin-treated diabetic rats was observed to be increased compared to the diabetes group, and there was an improvement in the seminiferous tubule structure in the former group (fig. 1d). 
Fig. 2. Representative photomicrographs of periodic-acid-Schiff-stained sections in the testes of rats. a Control group. b Melatonin-treated nondiabetic group. c Diabetic group. d Melatonin-treated diabetic group. When compared with the control group, the STBM increased thickness in the diabetic group (arrows), but melatonin reduced this increase in thickness (arrows).
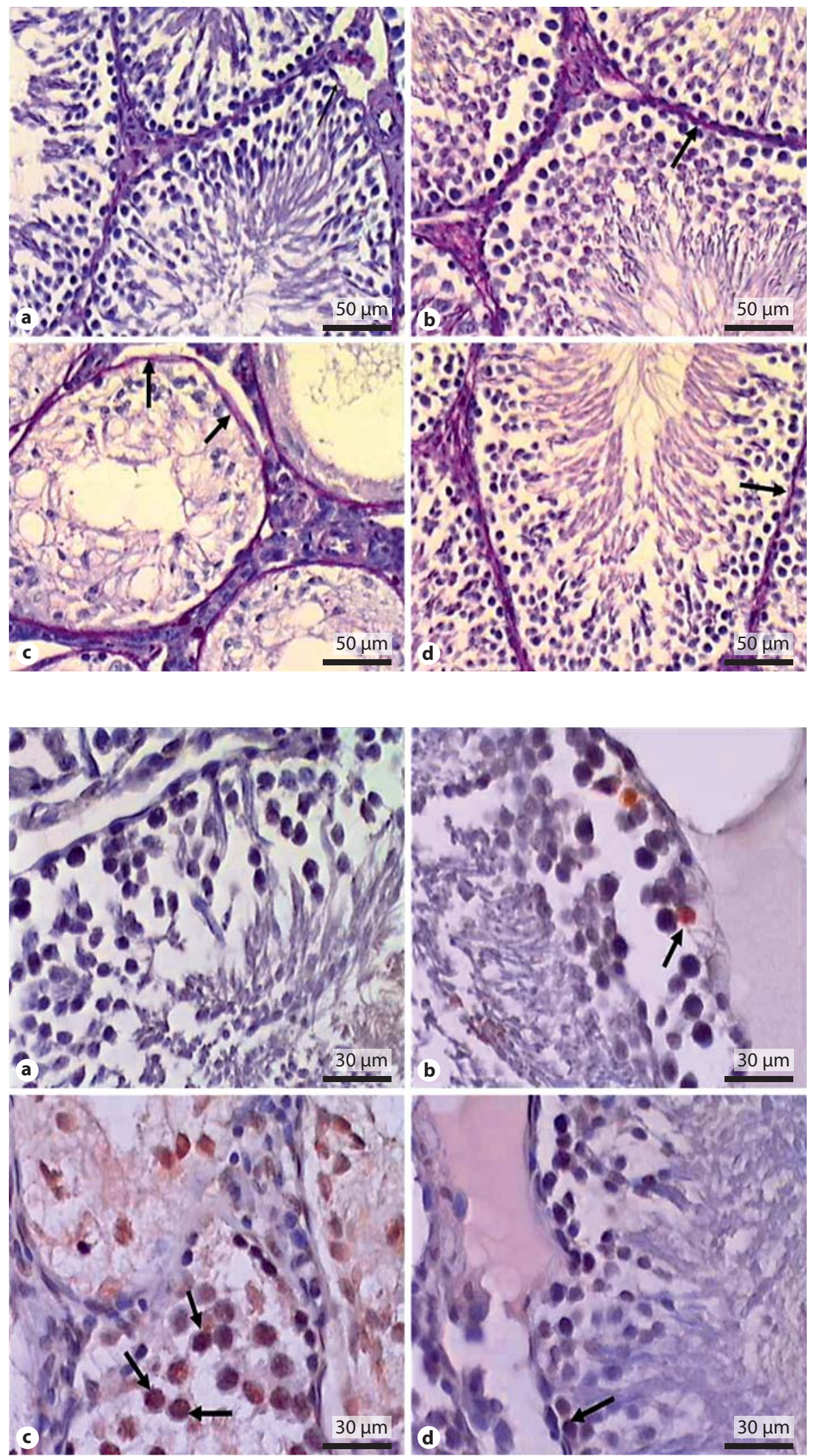

Fig. 3. Representative photomicrographs of TUNEL-stained sections in the testes of rats. a Control group. b Melatonin-treated nondiabetic group. c Diabetic group. d Melatonin-treated diabetic group. The number of TUNEL-labeled cells was reduced in the melatonin-treated diabetic group compared with the diabetic group (arrows).
Effect of Melatonin on Testicular Damage in STZ-Induced Diabetes Rats 
Table 1. Johnsen's scores, seminiferous tubule diameter (STD), thickness of STBM and TUNEL-positive cells in the testes of rats

\begin{tabular}{llllc}
\hline Groups & $\begin{array}{l}\text { Johnsen's } \\
\text { scores }\end{array}$ & $\begin{array}{l}\text { STD } \\
\mu \mathrm{m}\end{array}$ & $\begin{array}{l}\text { STBM } \\
\mu \mathrm{m}\end{array}$ & $\begin{array}{l}\text { TUNEL- } \\
\text { positive cells } \\
\%\end{array}$ \\
\hline $\mathrm{C}$ & $9.7 \pm 0.0$ & $277 \pm 7.4$ & $1.74 \pm 0.07$ & $0.7 \pm 0.3$ \\
$\mathrm{C}+\mathrm{Mel}$ & $9.5 \pm 0.1$ & $263 \pm 9.5$ & $1.76 \pm 0.06$ & $4.5 \pm 1.1$ \\
$\mathrm{DM}$ & $5.8 \pm 0.4^{\mathrm{a}}$ & $147 \pm 8.7^{\mathrm{a}}$ & $2.44 \pm 0.1^{\mathrm{a}}$ & $64.4 \pm 1.2^{\mathrm{a}}$ \\
$\mathrm{DM}+\mathrm{Mel}$ & $8.4 \pm 0.3^{\mathrm{b}}$ & $218 \pm 12.6^{\mathrm{c}}$ & $1.94 \pm 0.08^{\mathrm{b}}$ & $23.3 \pm 2.5^{\mathrm{b}}$ \\
\hline
\end{tabular}

Data are expressed as the mean \pm SEM. ${ }^{a}$ p $<0.001$ compared to control group, ${ }^{b} \mathrm{p}<0.001$ and ${ }^{\mathrm{c}} \mathrm{p}<0.01$ compared to diabetic group.

$\mathrm{C}=$ Control group $\mathrm{C}+\mathrm{Mel}=$ melatonin-treated nondiabetic group; $\mathrm{DM}=$ diabetic group; $\mathrm{DM}+\mathrm{Mel}=$ melatonin-treated diabetic group.

\section{Evaluation of Periodic Acid-Schiff Staining}

While STBM in the control (fig. 2a) and melatonintreated nondiabetic groups (fig. $2 \mathrm{~b}$ ) were observed to be normal, an increase in thickness was found in the diabetes (fig. 2c) and melatonin-treated diabetic groups (fig. 2d). On the other hand, the thickening in the melatonin-treated diabetic group was found to be less than in the diabetic group. In morphometric measurement, a significant increase in the thickness of the STBM was observed in the diabetic rats compared with the control rats $(\mathrm{p}<0.001)$, as shown in table 1. However, the thickness of the STBM was significantly decreased in the melatonintreated diabetic rats compared with the diabetic rats $(\mathrm{p}<$ $0.001)$.

\section{The Mean Seminiferous Tubule Diameter and \\ Johnsen's Criteria}

The seminiferous tubule diameter and Johnsen's criteria values of each group are shown in table 1. It was observed that both were significantly decreased in diabetic rats compared with the control group $(\mathrm{p}<0.001)$. However, these values were significantly increased in the melatonin-treated diabetic rats compared with the diabetic rats $(\mathrm{p}<0.01$ and $\mathrm{p}<0.001$, respectively).

Overall, no statistically significant differences were determined between the melatonin-treated nondiabetic group and the control group ( $\mathrm{p}>0.05)$.

The mean counts of polymorphonuclear leukocytes in groups 1 and 2 were $<1$ in the testes tissue area. Moreover, it was found to be $17 \pm 2$ and $8 \pm 0.8$ in groups 3 and 4 , respectively. Thus, the number of polymorphonuclear leukocytes was significantly decreased in group 4 when compared to group $3(\mathrm{p}<0.05)$.

\section{Evaluation of TUNEL Staining}

TUNEL-positive cells for each group are represented in table 1. The number of TUNEL-positive cells in the control group was negligible (fig. 3a). These cells were rarely observed in the melatonin-treated nondiabetic group (fig. 3b). No significant change was determined in germ cell apoptosis in the melatonin-treated diabetic group compared to the control group ( $p>0.05$; fig. $3 b$ ). In the diabetic group, TUNEL-positive cells were observed in all of the spermatogenic cell series in the seminiferous tubules ( $\mathrm{p}<0.001$; fig. $3 \mathrm{c}$ ) while a decrease in the TUNEL-positive cell number was observed in the melatonin-treated diabetic group with respect to the diabetic group ( $\mathrm{p}<0.001$; fig. $3 \mathrm{~d})$.

\section{Discussion}

The present study demonstrated that diabetes mellitus in male rats caused testicular dysfunctions, and melatonin treatment improved these functional deficits by providing protection against the impairment of seminiferous tubules and the loss of spermatogenic cell series. Besides, the number of TUNEL-positive cells in the germinal epithelium was significantly increased in the diabetic rats, an indication of apoptosis induced by diabetes mellitus in our adult male rats. However, the number of TUNEL-positive cells was reduced after melatonin treatment in diabetic rats.

The administration of melatonin, via any route, results in a rapid rise in blood melatonin concentrations. Since melatonin has both highly lipophilic and hydrophilic properties, it passes rapidly through all biological membranes and enters the cells and their subcellular compartments. The widespread subcellular distribution of melatonin may allow it to reduce oxidative damage in both the lipid and aqueous environments of the cell. This is an advantage for melatonin over some other antioxidants, which penetrate cells more slowly. Hussein et al. [19] showed that a single and high dose of melato$\operatorname{nin}(100 \mathrm{mg} / \mathrm{kg}$, i.p.) provided protection in X-ray-induced skin damage in rats. Several lines of evidence indicate that melatonin has an influence on cell proliferation and cell differentiation [20,21]. Melatonin induced a reduction in the total number of neuroblastoma cells in vitro. The inhibition was dose and time dependent and reached its maximum in cells treated for 6 days [ 20 , 
22]. In a study investigating the structural changes in the basement membrane, since no alterations were observed on the 2 nd and 3rd days and the changes became marked on the 7th day, this suggests an onset of alterations on the 5th day too [23]. Consequently, we observed that melatonin administered at the given dose $(10 \mathrm{mg} /$ $\mathrm{kg}$ ) and for the given duration (5 days) reduced the increase in basement membrane thickness of seminiferous tubules histologically and morphometrically in diabetic rats.

It is well known that diabetes mellitus induces testicular dysfunction by causing apoptotic cell death, atrophy of the seminiferous tubules, decreased tubule diameters and reduction of spermatogenetic cell series $[11,24]$. Seminiferous tubule atrophy and the decrease in spermatogenic cells were morphological indicators of spermatogenesis failure [11, 24]. Our results are consistent with those of previous studies. In our study, Johnsen's scores of diabetic rats were lower than 6 , which indicates the presence of testicular damage [25].

Uncontrolled and unnecessary apoptosis may occur during spermatogenesis resulting in testicular dysfunction. Therefore, apoptosis plays a crucial role in the pathogenesis of testicular dysfunction in diabetic males [11]. Specific DNA fragmentation at nucleosomal units is one of the most characteristic features of apoptosis [26]. Detection of DNA fragments in situ using the TUNEL assay [27] is undertaken to investigate active germ cell apoptosis induced by diabetes [11] and other stimulants $[10,28]$ in the testis. This method was used in the measurement of apoptosis in several organs other than the testis [14-16, 29]. Germ cell apoptosis is consistent with morphological analysis in the seminiferous tubules [30]. The germ cell degeneration shows distinct morphological signs such as margination and condensation of nuclear chromatin and phagocytosis by Sertoli cells without signs of inflammatory response [12]. In the present study, TUNEL-positive cells showed the typical morphological features of apoptosis such as chromatin condensation, cytoplasmic budding and apoptotic bodies. The number of TUNEL-positive cells in the germinal epithelium was significantly increased in diabetic males, indicating that germinal cell apoptosis was induced by diabetes mellitus in the adult male rat testes. There are markedly fewer TUNEL-positive cells in the diabetic rats treated with melatonin. It has previously been shown that diabetes mellitus increases oxidative stress in the diabetic male testis [31, 32]. Under an elevated oxidative stress status, reactive oxygen species cause cellular injury via several mechanisms including lipid peroxidation and oxidative damage of proteins and DNA [33]. Oxidative stress is recognized as a strong mediator of apoptosis [34]. Mitochondria play an important role in the apoptotic process. The mitochondrial dysfunction induced by oxidative stress can lead to the release of cytochrome $c$ and then caspase activation, which results in apoptotic cell death [34]. Malondialdehyde levels have been widely used as a marker of lipid peroxidation products and lipid peroxidation damage in tissue, cells and body fluids in both clinical and experimental studies [35-37]. In the present study, we demonstrated that melatonin prevents diabetes-induced germinal cell loss in the diabetic male rat. These findings indicate that the germinal cell-protective effects of melatonin may reflect its role as a free radical scavenger, an antioxidant, an antiapoptotic or an antiinflammatory agent [13-15].

A recent report has shown that melatonin inhibits neutrophil adhesion to vascular endothelial cells [38]. Ohta et al. [39] found an increase in neutrophil infiltration in liver tissues, which was assessed by measuring hepatic myeloperoxidase activity, which occurred in rats with 5 or 13 days of bile duct ligation. Melatonin given orally to rats with bile duct ligation attenuated the increase in hepatic myeloperoxidase activity. In our study, the number of polymorphonuclear leukocytes was significantly decreased in the melatonin-treated diabetic group when compared to the diabetic group.

The thickness of the STBM plays an important role in spermatogenesis. Diabetes increases thickening of the STBM [40, 41], and this thickness is accompanied by a decreased rate of sperm production and overall reduction in the size of seminiferous tubules. In the present study, light-microscopic examination revealed that thickness of the STBM increased in diabetic rat testes, but melatonin reduced this increase in thickness.

In conclusion, melatonin improves the testicular damage in diabetic male rats. To our knowledge, this is the first report indicating that melatonin improved diabetesinduced testicular dysfunction in diabetic rats. Melatonin can contribute to a balanced oxidant-antioxidant status and provide a useful therapeutic option to reduce the associated testes injury in patients with diabetes mellitus. 


\section{References}

1 Sexton WF, Jarow JP: Effect of diabetes mellitus upon male reproductive function. Urology 1997;47:508-513.

$\checkmark 2$ Baker HW: Reproductive effects of nontesticular illness. Endocrinol Metab Clin North Am 1998;27:831-850.

-3 Sainio-Pollanen S, Henriksen K, Parvinen M, Simell O, Pollanen P: Stage-specific degeneration of germ cells in the seminiferous tubules of non-obese diabetic mice. Int J Androl 1997;20:243-253.

4 Meyer K, Deutscher J, Anil M, Berthold A, Bartsch Kiess W: Serum androgen levels in adolescents with type I diabetes: relationship to pubertal stage and metabolic control. J Endocrinol Invest 2000;23:362-368.

5 Seethalakshmi L, Menon M, Diamond D: The effect of streptozotocin-induced diabetes on the neuroendocrine-male reproductive tract axis of the adult rat. J Urol 1987;138: 190-194.

-6 Oksanen A: Testicular lesions of streptozotocin diabetic rats. Horm Res 1975;6:138144.

7 Scarano WR, Messias AG, Oliva SU, Klinefelter GR, Kempinas WG: Sexual behaviour, sperm quantity and quality after short-term streptozotocin-induced hyperglycaemia in rats. Int J Androl 2006;29:482-488.

$\checkmark 8$ Sinha Hikim AP, Swerdloff RS: Hormonal and genetic control of germ cell apoptosis in the testis. Rev Reprod 1999;4:38-47.

$\checkmark 9$ Cai L, Hales BF, Robaire B: Induction of apoptosis in the germ cells of adult male rats after exposure to cyclophosphamide. Biol Reprod 1997;56:1490-1497.

$\checkmark 10$ Collin O, Damber JE, Bergh A: Effects of endothelin-1 on the rat testicular vasculature. J Androl 1996; 17:360-366.

-11 Cai L, Chen S, Evans T, Deng DX, Mukherjee $\mathrm{K}$, Chakrabarti S: Apoptotic germ-cell death and testicular damage in experimental diabetes: prevention by endothelin antagonism. Urol Res 2000;28:342-347.

-12 Allan DJ, Harmon BV, Roberts SA: Spermatogonial apoptosis has three morphologically recognizable phases and shows no circadian rhythm during normal spermatogenesis in the rat. Cell Prolif 1992;25:241250.

13 Reiter RJ, Tan DX, Osuna C, Gitto E: Actions of melatonin in the reduction of oxidative stress: a review. J Biomed Sci 2000;7:444458.

-14 Ozdemir D, Tugyan K, Uysal N, Sonmez U, Sonmez A, Acikgoz O, et al: Protective effect of melatonin against head trauma-induced hippocampal damage and spatial memory deficits in immature rats. Neurosci Lett 2005;385:234-239.
15 Tugyan K, Uysal N, Ozdemir D, Sonmez U, Pekcetin C, Erbil G, Sonmez A: Protective effect of melatonin against maternal deprivation-induced acute hippocampal damage in infant rats. Neurosci Lett 2006;398:145150.

16 Fischer TW, Zbytek B, Sayre RM, Apostolov EO, Basnakian AG, Sweatman TW, et al: Melatonin increases survival of $\mathrm{HaCaT}$ keratinocytes by suppressing UV-induced apoptosis. J Pineal Res 2006;40:18-26.

17 Armstrong D, Al-Awadi F: Lipid peroxidation and retinopathy in streptozotocin induced diabetes. Free Radic Biol Med 1991;11: 433-436.

18 Johnsen SG: Testicular biopsy score count - a method for registration of spermatogenesis in human testes: normal values and results of 335 hypogonadal males. Hormones 1970;1: 2-25.

19 Hussein MR, Abu-Dief EE, Abd El-Reheem $\mathrm{MH}$, Abd-Elrahman A: Ultrastructural evaluation of the radioprotective effects of melatonin against $\mathrm{X}$-ray-induced skin damage in Albino rats. Int J Exp Pathol 2005;86:45-55.

20 García-Santos G, Antolín I, Herrera F, Martín V, Rodriguez-Blanco J, del Pilar Carrera M, Rodriguez C: Melatonin induces apoptosis in human neuroblastoma cancer cells. J Pineal Res 2006;41:130-135.

21 Hill SM, Blask DE: Effects of the pineal hormone melatonin on the proliferation and morphological characteristics of human breast cancer cells (MCF-7) in culture. Cancer Res 1988;48:6121-6126.

-22 Sainz RM, Mayo JC, Tan DX, Lopez-Burillo S, Natarajan M, Reiter RJ: Antioxidant activity of melatonin in Chinese hamster ovarian cells: changes in cellular proliferation and differentiation. Biochem Biophys Res Commun 2003;302:625-634.

23 Richardson LL, Kleinman HK, Dym M: Altered basement membrane synthesis in the testis after tissue injury. J Androl 1998;19: 145-155.

24 Cameron DF, Murray FT, Drylie DD: Interstitial compartment pathology and spermatogenic disruption in testes from impotent diabetic men. Anat Rec 1985;213: $53-62$

25 Kehinde EO, Anim JT, Mojiminiyi OA, AlAwadi F, Shihab-Eldeen A, Omu AE, et al: Allopurinol provides long-term protection for experimentally induced testicular torsion in a rabbit model. BJU Int 2005;96:175180.

26 Wyllie AH, Kerr JF, Currie AR: Cell death: the significance of apoptosis. Int Rev Cytol 1980;68:251-306.

27 Gavrieli YS, Ben-Sasson SA: Identification of programmed cell death in situ via specific labeling of nuclear DNA fragmentation. J Cell Biol 1992;119:493-501.
28 Sobarzo CM, Lustig L, Ponzio R, Denduchis B: Effect of di-(2-ethylhexyl)phthalate on Ncadherin and catenin protein expression in rat testis. Reprod Toxicol 2006;22:77-86.

$>29$ Padillo FJ, Cruz A, Navarrete C, Bujalance I, Briceno J, Gallardo JI, et al: Melatonin prevents oxidative stress and hepatocyte cell death induced by experimental cholestasis. Free Radic Res 2004;38:697-704.

30 Russel LD, Alger LE, Nequin LG: Hormonal control of pubertal spermatogenesis. Endocrinology 1987;120:1615-1632.

31 Giugliano D, Ceriello A, Paolisso G: Oxidative stress and diabetic vascular complications. Diabetes Care 1996;19:257-267.

>32 Baynes JW, Thorpe SR: Role of oxidative stress in diabetic complications: a new perspective on an old paradigm. Diabetes 1999; 48:1-9.

33 Buttke TM, Sandstrom PA: Oxidative stress as a mediator of apoptosis. Immunol Today 1994;15:7-10

-34 Leon J, Acuna-Castroviejo D, Escames G, Tan DX, Reiter RJ: Melatonin mitigates mitochondrial malfunction. J Pineal Res 2005; 38:1-9.

\35 Garcia JJ, Reiter RJ, Guerrero JM, Escames G, Yu BP, Oh CS, Munoz-Hoyos A: Melatonin prevents changes in microsomal membrane fluidity during induced lipid peroxidation. FEBS Lett 1997;408:297-300.

36 Trimarchi H, Mongitore MR, Baglione P, Forrester M, Freixas EAR, Schropp M, Pereyra H, Alonso M: N-acetylcysteine reduces malondialdehyde levels in chronic hemodialysis patients - a pilot study. Clin Nephrol 2003;59:441-446.

37 Freudenthaler SM, Schreeb KH, Wiese A, Pilz J, Gleiter $\mathrm{CH}$ : Influence of controlled hypoxia and radical scavenging agents on erythropoietin and malondialdehyde concentration in humans. Acta Physiol Scand 2002;174:231-235.

$>38$ Lutofo CMC, Lopes C, Dubocovich ML, et al: Melatonin and $\mathrm{N}$-acetylserotonin inhibit leukocyte rolling and adhesion to rat microcirculation. Eur J Pharmacol 2001;430:351357.

39 Ohta Y, Kongo M, Kishikawa T: Melatonin exerts a therapeutic effect on cholestatic liver injury in rats with bile duct ligation. J Pineal Res 2003;34:119-126.

40 Abrahamson DR: Recent studies on the structure and pathology of basement membranes. J Pathol 1986;149:257-278.

41 Rohrbach DH, Martin GR: Structure of basement membrane in normal and diabetic tissue. Ann NY Acad Sci 1998;401:2203-2211.

Guneli/Tugyan/Ozturk/Gumustekin/ Cilaker/Uysal 